\title{
A Comparative Analysis of Macedonian and English Teachers' Implicit Theories of Pupils' Intelligence and Motivation
}

\author{
Ana Mickovska \\ University of Cambridge, UK \\ Contact:amickovska2@yahoo.com
}

\begin{abstract}
The paper represents a cross-cultural study of the similarities and differences in Macedonian and English teachers' beliefs about pupils' intelligence and the motivational strategies used in the classroom. Results indicate that Macedonian and English differ more in regards to the motivational strategies adopted, than to the implicit theories held. Findings tentatively suggest that the adoption of motivational strategies is primarily influenced by the doctrines promoted by the schooling system and to a minor degree by teachers' beliefs about pupils' intelligence and motivation.
\end{abstract}

Many authors (e.g. Pajares, 1992; Kagan, 1992; Calderhead, 1996) consider the construct of teachers' implicit theories (or beliefs) to be highly significant for the understanding of teachers' perceptions and consequently their behaviour in the classroom. It is assumed that teachers' implicit theories about teaching and learning begin to develop during their personal schooling experience through 'apprenticeship of observation' (Lortie, 1975; cited in Borg, 2004). During the many years spent as pupils, teachers have not only been learning the material from the subject areas they were taught in, but have also picked up pedagogical knowledge on the teaching and learning methods, strategies for motivating pupils etc.. Because the pedagogical knowledge has not been formally transmitted to them and they are unlikely to have attended to it in a systematic way, it is assimilated in an intuitive, semiconscious way and persists in the form of an implicit theory. Researchers (Richardson, 1996, as cited in Woolfolk Hoy \& Murphy, 2001; Calderhead, 1996; Kagan, 1992) have found that the teachers' formal training is not very influential in changing their already formed theories. Moreover, the implicit theories tend to influence the way in which teachers interpret and make use of the new information (Pajares, 1992).
The present research aims are to explore whether there are differences in the implicit conceptions of intelligence within teachers from two culturally diverse contexts (Macedonia and England), and in the strategies they use for motivating pupils. The differences in the two countries' schooling practices are irrefutable and range from the dominant methods of teaching, learning and pupil assessment, to the use of feedback. However, the question is whether they are an expression of the differences in teachers' beliefs, or simply a reflection of the countries' different schooling standards, which teachers are required to adapt to. A review of the literature indicated a deficiency of studies exploring the relationship of teachers' beliefs and practices, as well as an absence of cross-cultural approaches towards the issue. This study attempts to bridge some of the gaps in the current knowledge-base and offer suggestions on how the issue should be tackled in future.

\section{Theoretical Background}

Implicit Theories of Intelligence. The study employs a relatively new theoretical concept of implicit theories of intelligence, based on Dweck and 
Leggett's (1988) Model of Implicit Theories of Intelligence. The model offers a framework for analysing people's conceptions of intelligence in relation to their achievement motivation. The model is built upon the idea that people basically differ in their beliefs about the nature of intelligence. It differentiates between individuals who believe that their intelligence is fixed and hence out of their personal control and individuals who believe their intelligence is malleable and can be controlled and influenced by them. The first group is referred to as 'Entity theorists' and the second as 'Incremental theorists'. Depending on which of the two theories people support it creates a framework of interrelated structures and fosters 'judgements and reactions that are consistent with that framework' (Dweck, Chiu \& Hong, 1995, p. 268).

Elliott and Dweck (1988) suggest that people that perceive their intelligence as a fixed trait usually pursue 'performance goals' (attempting to create the impression of having adequate ability and avoid showing evidence of inadequacy); while the ones that believe their intelligence to be a malleable characteristic pursue 'learning goals' (aimed at improving their skills and knowledge and adopting new competencies in any learning situation). The basic difference here, as Elliott \& Dweck (1988) put it, is among actions directed towards proving ability as opposed to improving ability.

Dweck and Leggett (1988) argue that peoples' selftheories about intelligence are strongly related to the motivational style they are likely to develop. Entity theorists tend to adopt maladaptive motivational styles (i.e. learned helplessness or attenuated mastery), thinking there is nothing they can do to improve their ability and consequently their performance, so after a failure situation they simply give up trying or seek to find ways to hide their 'incompetence' from others. On the other hand, incremental theorists do not lose confidence in their ability after experiencing failure, but simply decide to make more effort the next time in order to improve their performance (i.e. adopt mastery motivational patterns).

These self-beliefs are found to be strongly influenced by the characteristics of the environment and the socializing practices a child is exposed to, especially the feedback from adults (e.g. parents, teachers) after success or failure situations. Specifically, feedback from the adult indicating a child's permanent characteristics (e.g. goodness, worth, intelligence etc.) might suggest that those traits are fixed and unchangeable. Alternatively, feedback directed towards the child's performance in terms of strategy employed or effort invested, suggests deficiencies which can be modified (Dweck et al., 1995). Thus, this theory can be very easily utilized to explain the teachers' strategies for motivating pupils, such as selecting tasks, providing feedback, and setting goals. Specifically, teachers who hold an entity view of intelligence would be likely to emphasize performance goals or 'looking smart', while teachers inclined towards the incremental perspective would be more likely to call attention to learning goals or 'becoming smart' (Dweck \& Bempechat, 1983; cited in Woolfolk Hoy \& Murphy, 2001).

Culture and achievement motivation. Numerous cross-cultural studies (e.g. Markus \& Kitayama, 1991; Pepitone \& Triandis, 1987; cited in Miller, 1996; Rodrigues, 1980; Yan \& Gaier, 1994; Tuss, Zimmer \& Ho, 1995) have found that the definitions of achievement motivation and the causes typically attributed to success and failure situations differ across cultures. The socially constructed conceptions (e.g. ability, effort) and the attributions for success and failure are believed to develop through the individual's everyday experiences by means of internalising the cultural knowledge and values. The most dominant mediators of cultural meanings are considered to be the socialising and schooling practices and the 'scientific' theories dominant in a specific context (Mugny \& Carugati, 1989). They act by socially (or culturally) predetermining the categories through which individuals perceive and explain their experiences (Moscovici, 1984). Boekartes argues that seen through the lenses of Dweck's model, Western (e.g. English, North American) socializing and schooling practices are more 'in line with an entity view of intelligence' (Boekartes 2003, p. 17), while the Eastern (e.g. Japanese, Chinese) practices fit better into the incremental framework, which conceives ability as malleable and improvable.

Pertinent to the present study, the TIMMS 1999 (IEA, 2000) results indicated that a significant majority (about 90\%) of the 14 year old pupils in Macedonia and England believed that working hard is a very important factor for good achievement in Maths and Science. However, a high percentage of the Macedonian pupils also believed that doing well in these subjects is related to possessing natural ability (80 \% for Maths and $74 \%$ for Science), contrasted to a significantly lower percentage of English pupils (47\% for Maths and 45\% for Science) that held this belief. Although these findings do not tell us much about the beliefs of teachers in the two countries, it is likely that teachers transmit these or corresponding beliefs (directly and indirectly) to the pupils through their classroom practices and the dominant schooling practices (see Appendix 1). Hence an exploration of the cultural specifics in the implicit theories of intelligence appears promising for providing a better understanding of the cultural specifics in the teachers' beliefs about pupils' intelligence and motivation. At the same time, it enables the relevance of Dweck and Leggett's (1988) Model of Implicit Theories of Intelligence to be tested in two culturally diverse contexts. 


\section{Method}

The study adopts a mixed-method design, which combines qualitative and quantitative data. It makes use of two existing questionnaires for measuring implicit theories of intelligence, combining them with vignettes requiring qualitative responses, designed especially for the purposes of the study. The focus of the study was placed on answering the following research questions:

1. Is one implicit theory of intelligence more dominant among teachers from England and Macedonia?
2. Is there a difference between the motivational strategies adopted by teachers from Macedonia and England?

\section{Sample}

The sample consisted of 74 secondary school teachers, 39 of which were from Macedonia (Skopje) and 35 from England (Cambridgeshire). The study relied on a convenience sampling. All teachers from the collaborating schools were invited to participate, regardless of the subject they teach, their age or years of experience as a teacher. The demographic characteristics of the sample are presented in Table 1.

Table 1. Demographic characteristics of the sample

\begin{tabular}{|l|l|l|l|}
\hline \multicolumn{2}{|c|}{ Demographic characteristic } & Macedonian sample & English sample \\
\hline \multirow{3}{*}{ Sex } & Female & 32 & 23 \\
\cline { 2 - 4 } & Male & 7 & 12 \\
\hline \multirow{5}{*}{ Subject area } & Maths and Natural Sciences & 18 & 10 \\
\cline { 2 - 4 } & Social Sciences & 3 & 9 \\
\cline { 2 - 4 } & Languages and Arts & 14 & 16 \\
\cline { 2 - 4 } & No response & 4 & 0 \\
\hline \multirow{5}{*}{ Age } & $<35$ & 11 & 14 \\
\cline { 2 - 4 } & $36-45$ & 6 & 7 \\
\cline { 2 - 4 } & $46<$ & 16 & 2 \\
\cline { 2 - 4 } & no response & 2 & 2 \\
\hline
\end{tabular}

\section{Measures}

The main data-collection instrument was a questionnaire (see Appendix 2) and consisted of two main parts, described below:

1. The 'Implicit theory scale' - consisted of six items designed to detect the implicit theory of pupils' intelligence a teacher holds. It comprised two subscales, aimed at examining two distinct aspects of the construct:

a) 'Malleability-of-intelligence-scale', consisted of two items adapted from Dweck's (1999) scale on implicit theories of intelligence for adults, but rephrased to refer to pupils. They asked for teachers' agreement on statements such as: No matter how much intelligence a pupil has, it can always be changed quite a bit. These items were constructed to detect whether teachers believe that pupils' intelligence can or cannot be changed.

b) 'Effort-ability-scale', consisted of four items adapted from Kurtz et al's (1990) study, aimed to detect the significance teachers place on ability and effort as factors influencing pupils' achievement (success). The items asked for teachers' opinion on vignettes portraying typical school situations (e.g. two pupils in your class are performing at approximately equivalent levels on their schoolwork. However, pupil A, whom you judge to be very bright, is not working very hard. On the other hand, pupil B whilst not so capable works very hard. Which pupil do you think is likely to be the most successful by the end of secondary school?).

For both of the sub-scales, a dichotomous choice of responses (Yes/No) was offered, with one option reflecting an entity theory and the other an incremental theory. However, given the limited response-choice, space was provided for respondents to offer a supplementary comment should they wish to elaborate their answers.

Scoring of the responses. Dweck (1999) conceptualises the construct of implicit theories of intelligence as dichotomous (consisting of two extreme categories). Hence, in her studies, subjects who do not score at either extreme are omitted from the analysis. In the present study, a similar method to Dweck's was employed for dividing the entity and 
incremental theorists. However, the respondents found to hold a 'mixed theory' (17\%) were considered to be important for the study and were not excluded from the analysis.

The two provided alternatives of the 'Implicit theory scale' items were coded as 1 if the response reflected an incremental theory and 0 if it reflected an entity theory. The scores on the six items were added. Hence, the total score ranged from 0 to 6 .

Respondents that scored from 0 to 2 were categorised as entity theorists and the ones that scored from 4 to 6 as incremental theorists. Teachers who responded as incremental theorists on half of the items and as entity theorists on the other half (i.e. received score 3) were categorised as mixed theorists (see Table 2).

Table 2. Thresholds for determining membership in different categories

\begin{tabular}{|c|c|c|c|c|}
\hline \multirow{2}{*}{$\begin{array}{l}\text { Main } \\
\text { scale }\end{array}$} & \multirow{2}{*}{$\begin{array}{l}\text { Implicit-theory-scale (implicit theory of pupils' } \\
\text { intelligence) }\end{array}$} & entity & mixed & incremental \\
\hline & & $0-2$ & 3 & $4-6$ \\
\hline \multirow{4}{*}{$\begin{array}{l}\text { Sub } \\
\text { scales }\end{array}$} & \multirow{2}{*}{$\begin{array}{l}\text { Malleability-of-intelligence-scale(belief that pupils' } \\
\text { intelligence is fixed or malleable) }\end{array}$} & fixed & mixed & malleable \\
\hline & & 0 & 1 & 2 \\
\hline & \multirow{2}{*}{$\begin{array}{l}\text { Effort-ability-scale (significance of pupils' ability } \\
\text { and effort for success) }\end{array}$} & $\begin{array}{l}\text { ability - more } \\
\text { significant }\end{array}$ & \begin{tabular}{|l}
$\begin{array}{l}\text { equally } \\
\text { significant }\end{array}$ \\
\end{tabular} & $\begin{array}{l}\text { effort - more } \\
\text { significant }\end{array}$ \\
\hline & & $0-1$ & 2 & 3-4 \\
\hline
\end{tabular}

On the basis of the score received on the 'Implicittheory-scale', teachers were categorised as holding: 1. Entity theory of pupils' intelligence: Belief that pupils' intelligence is a fixed trait, which cannot be changed through learning or hard work; accompanied with a belief that pupils' abilities are a primary factor for their success in school and/or later in life. 2. Incremental theory of pupils' intelligence: Belief that pupil's intelligence is malleable and can be changed through learning and hard work; accompanied with a belief that pupils' effort is a primary factor for their success in school and/or later in life.

3. Mixed theory of pupils' intelligence: Combination of the beliefs held by entity and incremental theorists, with predominance of one or the other framework depending on the situation.

2. 'Motivational strategies', the second part of the questionnaire, consisted of 12 items in the form of vignettes (hypothetical situations). They were constructed to detect teachers' beliefs and expectations regarding pupils' motivation and the practices they employ to motivate pupils. The items included in this part of the questionnaire were specifically designed for the purposes of the present study. They illustrated everyday classroom situations involving pupils' motivation and learning and requested that the teachers indicate their most typical response to each situation (e.g. A pupil had been performing well in your subject until she received a low mark for a piece of work. Since then, any time she is faced with a more challenging task, she gives up saying she isn't clever enough to complete it. What sort of tasks would you give her in order to raise her performance?).

Seven questions were open-ended and nine multiple choice. However, almost all of the multiple-choice questions also included a possibility for adding a comment. The decision to use open-ended questions as a primary source of information was based on the cross-cultural nature of the study. This type of question offers a freedom of expression which can easily be limited in the case of multiple-choice questions if the options provided are not culturally suitable. The responses were scored by assigning codes to each answer and were analysed as nominal data.

Translation of the questionnaire. The questionnaire was initially constructed in English. The English version was then given to a bilingual Macedonian translator, who translated it into Macedonian. Afterwards, the researcher and the translator went through all of the items and made some adaptations and clarifications. Certain phrases were slightly changed from the English version in order to make them culturally appropriate for the Macedonian teachers.

Psychometric characteristics of the scale. The internal reliability of the six items of the 'Implicittheory-scale' (calculated on the complete sample) is rather weak (Cronbach alpha $=0.486)$. However, it is slightly higher for the Macedonian sample (Cronbach alpha $=0.564$ ) than for the English sample (Cronbach alpha $=0.376)$. The internal reliability of the two subscales independently, is quite variable (see Table 3 ). 
Table 3. Internal reliability (Cronbach alpha) of the main scale and the two sub-scales

\begin{tabular}{|l|l|l|l|}
\hline & Complete sample & Macedonian sample & English sample \\
\hline Implicit-theory-scale & 0.49 & 0.56 & 0.38 \\
\hline Malleability-of-intelligence-scale & 0.64 & 0.21 & 0.87 \\
\hline Effort-ability-scale & 0.35 & 0.46 & 0.28 \\
\hline
\end{tabular}

Only the 'Malleability-of-intelligence-scale' for the English sample had high internal reliability (above 0.7). The relatively low internal consistency of the scale in general indicates the need for its improvement and standardisation for the two samples independently.

The scores on the two sub-scales were found to be significantly correlated in the case of the Macedonian sample $(\mathrm{r}=0.48, \mathrm{p}<0.01)$, but not within the English sample $(r=0.005, p>0.05)$. This suggests that the two elements they were measuring (malleability of intelligence and effort-ability relationship) may reflect a similar construct for the Macedonian teachers, whilst for the English teacher they are separate constructs. However, in order to verify these assumptions, they need to be tested on bigger and more representative samples of teachers. Bearing in mind these limitations of the 'Implicittheory-scale', caution should be exercised when interpreting results. They should not be generalised until the psychometric characteristics of the scale are adjusted. Therefore, a large part of the analysis is exploratory and makes use of the qualitative data to explore the conceptualisations of pupils' intelligence within the two samples of teachers.

\section{Results}

\section{Implicit theory of intelligence: Comparison of Macedonian and English teachers}

Table 4 shows the number of teachers found to hold entity, incremental and mixed theory of pupils' intelligence. Findings indicate that the incremental theory was found to be dominant among the teachers from both countries - around two-thirds of both groups indicate this preference. Differences between teachers from Macedonia and England in terms of adopting each of the three implicit theories, did not reach statistical significance $($ Chi-Square $=1.44$; $\mathrm{df}=2 ; \mathrm{p}=0.48)^{*}$.

Table 4. Implicit theory of pupils' intelligence

\begin{tabular}{|l|l|l|l|l|}
\hline \multicolumn{1}{|c|}{ Country } & \multicolumn{1}{c|}{ Entity } & Incremental & \multicolumn{1}{c|}{ Mixed } & Total \\
\hline Macedonia & $5(13 \%)$ & $29(74 \%)$ & $5(13 \%)$ & 39 \\
\hline England & $5(14 \%)$ & $22(63 \%)$ & $8(23 \%)$ & 35 \\
\hline Total & 10 & 51 & 13 & 74 \\
\hline
\end{tabular}

1 cell $(16,7 \%)$ has expected count less than 5 . The minimum expected count is 4,73

The analysis of the results on the 'Effort-ability' subscale did not reveal significant differences between the Macedonian and English teachers in the value of ability and effort for success (Chi-square $=0.335$; $\mathrm{df}=1 ; \mathrm{p}=0.72$ ). The majority of the Macedonian and English teachers emphasised effort as the main determinant of pupils' success (see Table 5). 
Table 5. Beliefs about the importance of ability and effort for success

\begin{tabular}{|l|l|l|l|l|}
\hline Country & $\begin{array}{c}\text { Ability - more important } \\
(*)\end{array}$ & \multicolumn{1}{|c|}{$\begin{array}{c}\text { Effort - more } \\
\text { important }\end{array}$} & Ability and effort - equally important & \multicolumn{1}{c|}{$(*)$} \\
\hline Macedonia $5(12 \%)$ & $27(70 \%)$ & $7(18 \%)$ & 39 \\
\hline England & $4(11 \%)$ & $22(63 \%)$ & $9(26 \%)$ & 35 \\
\hline Total & 9 & 49 & 16 & 74 \\
\hline
\end{tabular}

Categories marked with $\left(^{*}\right)$ were merged

Whilst scores on the main scale did not demonstrate differences between the two groups of teachers in the adoption of each of the implicit theories, the differences in scores on the 'Malleability-ofintelligence' sub-scale, reached significance (ChiSquare $=16.64, \mathrm{df}=2 ; \mathrm{p}=0.0002)$.

Table 6. Beliefs about malleability of intelligence

\begin{tabular}{|l|l|l|l|l|}
\hline Country & Entity & Mixed & Incremental & Total* \\
\hline Macedonia & $3(8 \%)$ & $16(41 \%)$ & $20(51 \%)$ & 39 \\
\hline England & $16(46 \%)$ & $4(11 \%)$ & $15(43 \%)$ & 35 \\
\hline Total & 19 & 20 & 35 & 74 \\
\hline
\end{tabular}

*Percentage calculations are based on the number of teachers who responded to the question

The distribution of responses, presented in Table 6 indicates that significantly more English teachers conceived intelligence as a fixed trait, differentiated from the concept of effort, regardless of the fact that many of them also believed in the potential of effort to cause a significant improvement in the pupils' performance (see Table 5).

\section{Motivational strategies adopted: Comparison of Macedonian and English teachers}

The most commonly used methods of setting tasks, giving feedback and assisting pupils who show maladaptive motivational patterns were compared cross-culturally. The open-ended responses were categorised in order to enable easier analysis. The findings indicated that dominant practices of the two groups of teachers differed in the majority of the achievement situations portrayed in the questionnaire. An equal percentage of teachers (34\%) from the two contexts believed in the potential of giving challenging tasks to motivate a pupil who has been inconsistent in his performance (see Table 7). However, significantly more Macedonian than English teachers emphasised that giving the pupil more assignments and regularly controlling his work should result in higher achievement. Hence, Macedonian teachers appear to be more inclined to employ authoritative methods (hard work, discipline) if they believe that a pupil has high abilities but does not work enough. On the other hand, English teachers were more prone towards setting more structured tasks and gradually increasing their difficulty in order for the pupil to regain his/her self-confidence.

Table 7. Method of work with a pupil who became discouraged after a low mark

\begin{tabular}{|l|l|l|l|l|l|l|l|}
\hline Country & $\begin{array}{c}\text { Easier } \\
\text { tasks }\end{array}$ & Moretasks & $\begin{array}{c}\text { Offer additional } \\
\text { explanation }\end{array}$ & $\begin{array}{c}\text { Gradually } \\
\text { increase } \\
\text { difficulty }\end{array}$ & Nothing/unspecified & $\begin{array}{c}\text { More } \\
\text { structured } \\
\text { tasks }\end{array}$ & Total* \\
\hline Macedonia & $4(11 \%)$ & $18(50 \%)$ & $6(17 \%)$ & $4(11 \%)$ & $4(11 \%)$ & 0 & 36 \\
\hline England & $5(16 \%)$ & 0 & 0 & $17(53 \%)$ & $2(6 \%)$ & $8(25 \%)$ & 32 \\
\hline Total & 9 & 18 & 6 & 21 & 6 & 8 & 68 \\
\hline
\end{tabular}

*Percentage calculations are based on the number of teachers who responded to the question 
Macedonian teachers reported using teacher-directed feedback (e.g. 'I'm very satisfied with your work') more than the English teachers in cases where a pupil completes a difficult task (see Table 8). The use of this externally-based feedback as a method for encouragement can be potentially dangerous for the pupils' goal orientation, because it may communicate a message that the pupil's performance is a means to primarily satisfy the teacher. Hence, it would be likely to direct the pupils towards 'extrinsic involvement' (Marshal and Weinstein, 1984: 317) (e.g. trying to satisfy the teacher's expectations), instead of learning goals (e.g. aiming to satisfy their intrinsic needs for learning).

Table 8 . Feedback to a pupil after completing a difficult task

\begin{tabular}{|l|l|l|l|l|l|l|}
\hline Country & $\begin{array}{c}\text { You have } \\
\text { worked hard }\end{array}$ & $\begin{array}{c}\text { I'm very satisfied } \\
\text { with your work }\end{array}$ & $\begin{array}{c}\text { You have used a good strategy } \\
\text { / approached the task well }\end{array}$ & $\begin{array}{c}\text { You are so } \\
\text { clever }\end{array}$ & $\begin{array}{c}\text { Depends on } \\
\text { the task }\end{array}$ & Total \\
\hline Macedonia & $9(24 \%)$ & $15(38 \%)$ & $6(15 \%)$ & $6(15 \%)$ & $3(8 \%)$ & 39 \\
\hline England & $11(31 \%)$ & $2(6 \%)$ & $15(43 \%)$ & $1(3 \%)$ & $6(17 \%)$ & 35 \\
\hline Total & 20 & 17 & 21 & 7 & 9 & 74 \\
\hline
\end{tabular}

Furthermore, the majority of the Macedonian teachers reported motivating pupils for a higher performance by emphasising their efforts and suggesting that they need to work harder in the case of a pupil that works very hard, but could not manage to improve his/her mark (see Table 9).

Table 9. Feedback to a pupil who wants to improve his mark

\begin{tabular}{|l|l|l|l|l|l|l|l|}
\hline Country & $\begin{array}{c}\text { Keep } \\
\text { trying/working } \\
\text { hard }\end{array}$ & $\begin{array}{c}\text { Study with } \\
\text { understanding }\end{array}$ & $\begin{array}{c}\text { Reward for } \\
\text { persistence }\end{array}$ & $\begin{array}{c}\text { Point out } \\
\text { mistakes, offer } \\
\text { suggestions }\end{array}$ & $\begin{array}{c}\text { Offer } \\
\text { extra } \\
\text { help }\end{array}$ & $\begin{array}{c}\text { Show } \\
\text { assessment } \\
\text { criteria }\end{array}$ & Total* \\
\hline Macedonia & $26(56 \%)$ & $10(22 \%)$ & $4(9 \%)$ & $5(11 \%)$ & $1(2 \%)$ & 0 & 46 \\
\hline England & $8(19 \%)$ & 0 & 0 & $15(36 \%)$ & $\begin{array}{l}11 \\
(26 \%)\end{array}$ & $8(19 \%)$ & 42 \\
\hline Total & 34 & 10 & 4 & 20 & 12 & 8 & 88 \\
\hline
\end{tabular}

*Percentage calculations are based on the number of teachers who responded to the question

This form of feedback is regarded as efficient in promoting adaptive motivational patterns (Dweck, 1975; Muller \& Dweck, 1998), but it's effects are believed to be strengthened if combined with comments on the strategy for performing the task (Dweck, 1999). However, Macedonian teachers rarely reported providing explicit feedback focused on the strategy or the specific aspects of the performance that needed to be improved. This could perhaps in some cases lead the pupils to frustration, if they do not manage to improve their performance despite of the effort invested (Stipek, 1997). Therefore, some of the teachers stated their readiness to increase a pupil's mark simply on the basis of the effort invested, even if the pupil lags in the performance (e.g. 'He will be rewarded for his persistence'). This practice of rewarding motivation as opposed to performance outcomes is relatively common in the Macedonian schooling system because the absence of national assessment standards allows teachers to develop their personal evaluation criteria. Hence, because effort is considered important and teachers are not provided with an opportunity to assess it as a separate factor, some decide to add it to the mark for academic performance.

English teachers, on the other hand, are required to adhere to the national standards for performance evaluation and strictly assess the outcomes. However, they usually have an opportunity to provide a separate comment referring to the pupil's work rate and behaviour. Perhaps this is the reason why they, in general, appear to separate the effort-feedback from giving advice regarding the strategy for performing the task. Teachers tend to offer detailed and constructive feedback on the pupil's performance by: telling the pupil specifically what he needs to do to improve his mark, offering additional help with his learning, acquainting the pupil with the assessment criteria to compare his work against, etc.

The English teachers' approach is more in line with 
the idea of developing the pupils' competences for self-regulation and self-assessment (by setting personal goals, competing against oneself etc.), and is hence more likely to guide the pupils towards pursuing learning goals (Ames, 1992; Pintrich \& Zusho, 2001).

\section{Discussion}

From the findings presented it can be concluded that although almost half of the English teachers were found to hold a fixed conception of intelligence, the strategies adopted by the majority of them were in line with the incremental theory principles and were focused on developing learning goals. Their feedback in most of the situations was directed towards the pupils' internal and changeable features (e.g. effort, strategy) and aimed at developing their potential for self-regulation and self-assessment. Perhaps the dominant belief in the importance of effort in achieving success exerts a stronger influence on their motivational strategies. However, it is also possible that the adoption of motivational strategies was mainly externally influenced by the schooling system. For example, the majority of English teachers reported that they would employ contemporary and systematic motivational methods and tended to use scientifically-based vocabulary in their responses, which perhaps reflected the values and standards explicitly promoted by the English schooling authorities (e.g. AfL principles - QCA, 2007), and may not necessarily be related to the teachers' personal beliefs.

On the other hand, Macedonian teachers, faced with an absence of explicitly promoted contemporary educational standards and values ; appear to have remained faithful to the traditional methods: additional work, teacher control of the pupil's work, and not getting too involved in the pupil's motivational problems. The routinely used 'traditional' methods, perhaps interacted with their generally held incremental beliefs about pupils' ability and resulted in employing less systematic feedback strategies, which might even be contradictory in certain aspects.

Specifically, whilst the majority of Macedonian teachers were found to frequently emphasise pupils' effort in their feedback, many of them also tended to stress their expectations and/or satisfaction with the pupil's work. In the former strategy, the incentive for the pupil's performance is located internally (within the pupil), while in the latter - externally (within the teacher). Teacher-directed feedback might lead the pupils to experience the praise as external and controlling, which might decrease their intrinsic motivation and 'impose an external performance pressure' (Thompson 1997, p. 56). Hence, the combination of the two dominant strategies might lead to development of maladaptive motivational patterns in pupils (e.g. investing effort for the purpose to satisfy the teacher's expectations).

These findings suggest that teachers' beliefs about pupils' intelligence may not always be reflected in their strategies for motivating pupils - such strategies often appear to be more related to the standards promoted by the schooling system. Hence, if the system provides the teachers with explicit guidelines on how they should react in specific situations involving pupils' learning and motivation, they are likely to adopt some of them even if they do not completely correspond to their personal beliefs. In contrast, if the system does not offer concrete guidelines, teachers will be more likely to act intuitively, but not necessarily in a systematic manner.

\section{Limitations of the study and suggestions for improvement}

Apart from the general limitations which may arise from using a questionnaire as a data-collection method (see Robson, 2006), certain problems, which are specific for the current study will be highlighted. Primarily, as a result of deficiency of previous similar studies and relevant instruments for data collection, the bulk of the questionnaire items had to be designed specifically for the purposes of the research. This, coupled with limitations in the time available, prevented the standardisation of the instrument for the two populations of teachers. Hence, in order for the questionnaire (especially the 'Implicit-theory-scale') to be used in future, efforts need to be made to increase the internal consistency of the scale and the discriminatory power of individual items in order for the scale to develop into a more valid and reliable measure of the construct. Secondly, the questionnaire data indicated that the responses of the teachers from the two contexts differed more on the open-ended, than on the closed questions. In addition, the responses on the former had offered richer data and provided a better comprehension of how each question was understood by the respondents. Hence, it is likely that the openended questions elicited more valid responses, because they do not impose pre-packed options, but instead rely on the teachers' automatic reaction on the question. This corresponds to other authors' claims that the qualitative research methods (e.g. open-ended questions, vignettes, in-depth interviews) are superior in cross-cultural research, especially in the beginning phases (Bond, 1984), and are more efficient than the quantitative methods for exploring personal concepts such as beliefs (Pajares, 1992; Chan \& Elliot, 2002). Thirdly, the sampling was conducted on the basis of convenience and included only schools from one city in Macedonia and one county in England. This fact limits the possibility of generalising the findings on the level of countries. Hence, the research should be 
seen as a pilot to explore the reliability of existing measures.

Finally, the discrete nature of the items prevented the possibility of conducting a more complex statistical analysis. This restricted the examination of the potential relationships between the main variables, implicit theories and motivational strategies. The Chisquare test also required merging many of the categories in order to determine the statistical significance, which had resulted in impoverishing some of the data.

\section{Conclusion}

There were no differences in the dominant implicit theory of pupils' intelligence held by the Macedonian and the English teachers. The majority of teachers were found to hold an incremental theory and value effort as a primary means for high pupil achievement. However, more English than Macedonian teachers conceptualised intelligence as a fixed trait, differentiated from the concept of effort. Teachers from the two countries were found to differ in their adoption of motivational strategies in the classroom on most of the achievement situations presented in the questionnaire. In general, strategies adopted by the English teachers were found to be more related to the incremental framework and focused on developing learning goals. Strategies adopted by the Macedonian teachers were less consistent, in that some of them were in line with the entity and others with the incremental framework. It can be tentatively concluded that the dominant schooling doctrine appears to exert a stronger influence on the teachers' adoption of motivational strategies, than their implicit theories.

\section{References}

Ames, C. (1992) Classrooms: Goals, structures, and student motivation. Journal of Educational Psychology, 84 (3), 261271.

Boekartes, M. (2003) How do students from different cultures motivate themselves for academic learning, In F. Salili and R. Hoosain (Eds.) Teaching, learning and motivation in a multicultural context, Information Age Publishing, Greenwich, Connecticut.

Borg, M. (2004) The apprenticeship of observation. ELT Journal, Vol. 58(3), Oxford University Press, 274-276. http://eltj.oxfordjournals.org/cgi/reprint/58/3/274.pdf (Accessed 25 May, 2007).

Buchmann, M. (1987) Teaching knowledge: The lights that teachers live by, Oxford Review of Education, Vol. 13 (2), 151164. Stable URL:

http://links.jstor.org/sici?sici=03054985\%281987\%2913\%3A2\%3 C151\%3ATKTLTT\%3E2.0.CO\%3B2-K (Accessed 3 June, 2007)

Burhans, K. and Dweck, C.S. (1995). Helplessness in early childhood: The role of contingent worth, Child Development, 66, 1719-1738.

Butler, R. (2000) Making judgments about ability: The role of implicit theories of ability in moderating inferences from temporal and social comparison information, Journal of
Personality and Social Psychology, 78, 965-978.

Clark, C. and Peterson, P. (1986) Teachers' thought processes, In M. Wittrock (Ed.) Handbook of Research on Teaching, Macmillan, New York.

Delceva Dizdarevic, J., Adamcevska, S., Damovska, L. (2006) National report - Macedonia In P. Zgaga (Ed.) The Prospects of Teacher Education in South-east Europe, Pedagoska Fakulteta Univerze v Ljubljani, Ljubljana.

Dweck, C.S., \& Bempechat, J. (1983). Children's theories of intelligence: Implications for learning. In S. Paris, G. Olson, and H. Stevenson (Eds.) Learning and motivation in children. Hillsdale, NJ: Erlbaum.

Dweck, C.S., and Leggett, E.L. (1988). A social-cognitive approach to motivation and personality, Psychological Review, 95, 256-273.

Dweck, C. S., Chiu, C., and Hong, Y. (1995). Implicit theories and their role in judgments and reactions: A world from two perspectives. Psychological Inquiry, 6, 267-285.

http://links.jstor.org/sici?sici=1047840X\%281995\%296\%3A4\%3C 267\%3AITATRI\%3E2.0.CO\%3B2-7 (Accessed 20 April, 2007)

Dweck, C. (1999) Caution: Praise can be dangerous, American

Educator, Spring, American Federation of Teachers. http://www.aft.org/pubs-

reports/american_educator/spring99/PraiseSpring99.pdf /Accessed 4 November, 2006).

Dweck, C.S. (1999) Self-Theories: Their role in motivation, personality and development. Taylor and Francis/Psychology Press, Philadelphia.

Elliott, E.S., \& Dweck, C.S. (1988) Goals: An approach to motivation and achievement, Journal of Personality and Social Psychology, 54, 5-12.

Elliot, J.G., Hufton, N. (2001) 'The kids are doing all right': differences in parental satisfaction, expectation and attribution in St. Petersburg, Sunderland and Kentucky, Cambridge Journal of Education, 31 ( 2), 179-204.

Holloway, S. (1988) Concepts of ability and effort in Japan and the United States, Review of Educational Research, Vol. 58, No. 3 327-345.

Stable URL: $\quad$ http://links.jstor.org/sici?sici=00346543\%28198823\%2958\%3A3\%3C327\%3ACOAAEI\%3E2.0.CO \%3B2-4(Accessed 5 May, 2007).

Heyman, G.D., Dweck, C.S., \& Cain, K. (1992) Young children's vulnerability to self- blame and helplessness. Child Development, 63, 401-415.

IEA: International Association for the Evaluation of Educational Achievement (2000) TIMMS 1999: Student Background with Science Achievement, International Study Center, Lynch School of Education, Boston College.

Kurtz, B.E., Schnider, W., Carr, M., Borkowski, G. and Rellinger, E. (1990) Strategy instruction and attributional beliefs in West Germany and the United States: Do teachers foster metacognitive development? Contemporary Educational Psychology, 15, 268-283.

Moscovici, S. (1984) The phenomenon of social representations. In S. Moscovici and R.M. Farr Social Representations, Cambridge University Press, Cambridge.

Mugny, G. and Carugati, F. (1989) Social representations of intelligence, Cambridge University Press, Cambridge

Mueller, C. M. and Dweck, C. S. (1998) Intelligence praise can undermine motivation and performance. Journal of Personality and Social Psychology, Vol.75, 33-52.

Nicholls, J.G. and Miller A. (1984) Conceptions of ability and achievement motivation, In Ames, R.E and Ames, C. (Eds.) Research on motivation in education: Student motivation. Vol. Academic press, New York.

Pajares, M.F. (1992) Teachers' belief and educational research: Cleaning up a messy construct, Review of Educational Research, 62 (3), 307-332.

Pepi, L., Faria, A. and Alesi, M. (2006) Personal conceptions of intelligence: Cross- cultural comparisons between Portuguese and Italian Students, Social Behavior and Personality.

http://findarticles.com/p/articles/mi qa3852/is 200601/ai n171813 63 (Accessed 3 June, 2007).

Sternberg R. (2000) Handbook of Intelligence. Cambridge 
University Press, Cambridge.

Thompson, T. (1997) Do we need to train teachers how to

administer praise? Self-worth theory says we do. Learning and Instruction. Vol. 1 (1), 49-63.

Woolfolk Hoy, A. and Murphy, P. K. (2001). Teaching educational psychology to the implicit mind. In R. Sternberg and B. Torff

(Eds.) Understanding and teaching the implicit mind, Lawrence Erlbaum, Mahwah, NJ.

Yates, Moore and McCabe (1999) The practice of statistics (1st Ed.). W.H. Freeman, New York. 